\title{
A service-oriented approach to assessing the Infrastructure Value Index
}

R. Amaral*, H. Alegre** and J. S. Matos*

\author{
*Instituto Superior Técnico, University of Lisbon (IST-UL), Av. Rovisco Pais, 1049-001 Lisbon, Portugal \\ (E-mail: rita.amaral@live.com; jose.saldanha.matos@tecnico.ulisboa.pt) \\ **National Laboratory for Civil Engineering, Av. Brasil, 101, 1700-066 Lisbon, Portugal \\ (E-mail: halegre@lnec.pt)
}

\begin{abstract}
Many national and regional administrations are currently facing challenges to ensure long-term sustainability of urban water services, as infrastructures continue to accumulate alarming levels of deferred maintenance and rehabilitation.

The Infrastructure Value Index (IVI) has proven to be an effective tool to support long-term planning, in particular by facilitating the ability to communicate and to create awareness. It is given by the ratio between current value of an infrastructure and its replacement cost. Current value is commonly estimated according to an asset-oriented approach, which is based on the concept of useful life of individual components. The standard values assumed for the useful lives can vary significantly, which leads to valuations that are just as different. Furthermore, with water companies increasingly focused on the customer, effective service-centric asset management is essential now more than ever.
\end{abstract}

This paper shows results of on-going research work, which aims to explore a service-oriented approach for assessing the IVI. The paper presents the fundamentals underlying this approach, discusses and compares results obtained from both perspectives and points to challenges that still need to be addressed.

Keywords

Urban water services; long-term planning; asset valuation; service-oriented approach

\section{INTRODUCTION}

Mounting international evidence suggests that the integrity of urban water infrastructures is at risk as they have accumulated alarming levels of deferred maintenance and rehabilitation (e.g. AWWA, 2012; CSA, 2014). In Portugal, the recent national strategic plan for the sector (MAOTE, 2014) warns of a clearly insufficient rehabilitation rate. For the current rate to be sustainable, pipes would need to last on average 100 and 200 years for water and wastewater networks respectively. Furthermore, more than 3.5 million people (over $33 \%$ of the population) are served by utilities that do not ensure cost recovery. A large number of utilities do not even know the true cost of their services. As a result, many national and regional administrations are currently facing challenges to ensure long-term sustainability of urban water services.

Service sustainability requires a concerted effort to improve long-term planning, which involves, among other aspects, the assessment of: the value of the infrastructure over time; the need for reinvestments; and the impact of long-term reinvestment policies (Alegre et al., 2014). Different approaches to supporting long-term planning have been proposed over time (e.g. PARMS-PLANNING - Burns et al., 2003; KANEW - Kropp and Baur, 2005) but dealing with the balance between performance, risk and cost and with the integration of linear (e.g. pipes) and vertical assets (e.g. treatment plants, pumping stations) in a combined and coherent manner is still a major challenge. Besides, the water industry must improve its ability to communicate the 
reinvestment needs to policy makers and utility CEOs. Whereby, it is essential that simple and understandable approaches and tools are available.

The Infrastructure Value Index (IVI), proposed by Alegre (2008) and broadly explored in recent years in various $R \& D$ and industry projects, has proven to be an effective tool to support long-term planning, in particular by facilitating the ability to communicate and to create awareness. IVI is the ratio between the current value of an infrastructure and its replacement cost and may conceptually be assessed in several different ways, derived from two main perspectives: asset-oriented and service-oriented.

In the asset-oriented approach, the calculation of the current infrastructure value is based on the concept of useful life of individual components. This approach has the advantage of being very intuitive and easy to use. However, the standard values assumed for the useful lives can vary significantly, which leads to an estimation of current value of an infrastructure and an estimation of reinvestment requirements that are just as different. In fact, the useful lives should be an output of service adequacy rather than an input for investment planning. Furthermore, with water companies increasingly focused on the customer, effective service-centric asset management is essential now more than ever (e.g. Jones et al., 2014).

This paper shows results of on-going research work, which aims to explore a service-oriented approach for assessing the IVI. The paper presents the fundamentals underlying this approach, discusses and compares results obtained from both perspectives and points to challenges that still need to be addressed.

\section{WHAT IS THE IVI AND HOW TO ASSESS IT?}

The Infrastructure Value Index is the ratio between the current (fair) value of an infrastructure and the replacement cost on modern equivalent asset basis (Alegre, 2008), as stated in (1).

Infrastructure Value Index $(\%)=\frac{\text { Infrastructure Current (fair) Value }}{\text { Infrastructure Replacement Cost }}$

IVI shall refer to a specific date, as it changes over time. The Infrastructure Current Value would be, in a competitive market activity, its market value. In a monopolistic activity, as in urban water services, alternative valuation approaches must be adopted. The Infrastructure Replacement Cost is the expected cost of a modern equivalent if the infrastructure was built in the year IVI refers to.

Conceptually, the IVI is a very simple and easy to understand index, enabling communication between stakeholders. It helps asset managers to inform decision makers about the long-term impacts of current and alternative levels of financing and management strategies. The evolution of IVI over time allows it to be understood if the level of investment is of the same order, higher or lower than the rate at which the asset's service potential is being consumed. Besides, it allows the comparison, in a long-term time window, of utilities with each other, infrastructures of a different nature (e.g., water supply with wastewater or storm water), or different areas of the systems (e.g., drainage sub basins, district metering areas).

Although formally simple, IVI can be assessed in many different ways, derived from two main perspectives, as discussed in Alegre et al. (2014):

- Asset-oriented: calculation based on useful life of each asset, depreciation curves and replacement costs for each category of assets; 
- Service-oriented: calculation based on performance of functional units of the infrastructure and cost and risk considerations.

The following sections briefly present and discuss these two basic formulations and the conditions applied in the analysis carried out on this study.

\section{Asset-oriented approach}

Whenever an asset-oriented strategy is applied, IVI may be determined considering the individual contribution of each asset, as presented in (2).

$$
I V I(t)=\frac{\sum_{i=1}^{N}\left(r c_{i, t} \cdot r u l_{i, t} / e u l_{i}\right)}{\sum_{i=1}^{N} r c_{i, t}}
$$

where: $t$ : reference time; IVI(t): Infrastructure Value Index at time $t ; N$ : Total number of assets; $r c_{i, t}$ : replacement cost of asset $i$ at time $t ;$ rul $_{i, t}$ : residual useful life of asset $i$ at time $t$; eul $i$ : expected useful life of asset $i$.

This formulation, presented in detail in Alegre et al. (2014), is implemented in the open-source AWARE-P software (available at www.baseform.org) and has been successfully applied in many water utilities. Figure 1 shows a screenshot of an application of the IVI tool. It illustrates the IVI (yellow line) and the reinvestment needs (pink bars) in a scenario where assets were replaced at the end of their expected lives. Different rehabilitation strategies can be tested and compared.

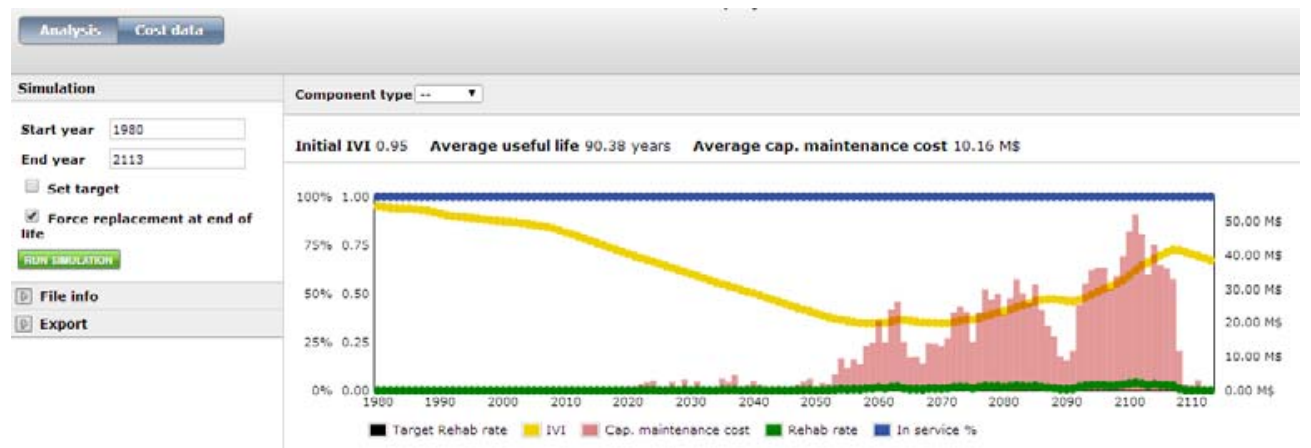

Figure 1. AWARE-P IVI tool.

An essential part of the asset-oriented formulation is the definition of useful lives. In the context of water and wastewater services, determining when asset's useful life will end is no simple task, as assets do not "die". The useful life ends when assets are no longer fit for purpose due to their condition (e.g. leaks, structural resistance), capacity, ease of operation and maintenance, relative balance between risk and renewal costs, etc. Then, there is no single criterion to objectively determine the end of life.

Several approaches have been proposed for modelling remaining useful life (a review of these models can be found in WERF, 2009). Available models tend to focus on pipe breaks, as it is the main indicator used for pipe renewal decisions by utilities (e.g. USEPA, 2013). For small diameter pipes, commonly with relatively low replacement costs and consequences of failure, statistical failure models are an economically viable approach (e.g. USEPA, 2013). In case of high risk pipelines, with costly and severe consequences of failure, more extensive and complex approaches are often recommended (e.g. Kane et al., 2014). The abovementioned models require detailed data 
and a level of training and expertise that are not always available within utilities (e.g. Ambrose et al., 2010; USEPA, 2013). As a result, standard useful life values based on expert opinion are still frequently applied in the water industry to estimate the current value of an infrastructure and the long-term renewal requirements (e.g. Renaud et al., 2014). This is the case in Portugal where most utilities often have to cope with incomplete or limited historical data.

Within the scope of iGPI 2015, Portugal's 2015 National Initiative for Infrastructure Asset Management (www.iniciativagpi.org), utilities were challenged to calculate the IVI of their infrastructures. In this regard, a broad discussion around 'useful lives' was carried out. Technicians from participating utilities were asked to assign useful lives for different categories of assets, aiming to achieve a global consensus on this issue. The results obtained are shown in Table 1. Table 1 also presents reference values in New South Wales (NSW, 2014) for comparison purposes.

Table 1. Useful lives adopted in iGPI and reference values referred in NSW (2014).

\begin{tabular}{|c|c|c|c|}
\hline \multirow{2}{*}{$\frac{\text { Asset }}{\text { Treatment works }}$} & \multirow[t]{2}{*}{ iGPI } & \multicolumn{2}{|c|}{$\begin{array}{c}\text { NSW } \\
\text { Water supply (WS); Wastewater (WW) }\end{array}$} \\
\hline & & & \\
\hline Structure & 75 & 70 & 50 \\
\hline Mechanical \& electrical & $10-15$ & 30 & 20 \\
\hline $\begin{array}{l}\text { Pumping stations } \\
\text { Structure } \\
\text { Mechanical \& electrical }\end{array}$ & $\begin{array}{c}75 \\
17 \mathrm{WS} ; 10-15 \mathrm{WW} \\
\end{array}$ & $\begin{array}{l}50 \\
25\end{array}$ & $\begin{array}{l}70 \\
25\end{array}$ \\
\hline Reservoirs & 75 & \multicolumn{2}{|c|}{100 Structure; 40 roof } \\
\hline \multicolumn{4}{|l|}{ Pipes } \\
\hline Ductile iron & 60 & \multirow{8}{*}{$\begin{array}{l}80 \text { new mains; } \\
50 \text { relined mains }\end{array}$} & 40 \\
\hline Concrete & 60 & & 45 \\
\hline Steel & 60 & & - \\
\hline Polyvinyl Chloride & 50 & & - \\
\hline Polyethylene & 50 & & - \\
\hline Asbestos cement & $45-55$ & & 45 \\
\hline Vitrified clay & $50-60$ & & 70 \\
\hline Relined & 50 & & 50 \\
\hline
\end{tabular}

As can be seen above, the standard values adopted can vary significantly, which leads to infrastructure valuations that are just as different. In particular regarding pipe assets, the following main issues have emerged from the discussion:

- For the same material, have water and wastewater pipes different useful lives? Some have argued that wastewater pipes may have lower useful lives due to the more aggressive environment. Others argued that it should be the opposite as risk tolerance in water pipes is lower.

- For the same pipe material should useful lives vary for different diameters? Again, some have argued that larger diameters have higher useful lives because of better quality of construction, greater thicknesses, better maintenance practices, etc. Others argued that it should be the opposite since risk tolerance of larger diameters is lower.

It became quite evident that useful life is a complex and multifaceted concept. With all this, and in a context of preliminary analysis, it was decided not differentiate useful lives for water and wastewater pipes and for different diameters.

\section{Service-oriented approach}

There are two important principles derived from urban water infrastructure properties:

(i) It's all about service, i.e. infrastructures only exist to provide a service to the public. 
(ii) Urban water assets are network assets, creating the need to manage the assets on the basis of ensuring service and risk levels, rather than individual components (e.g. Reksten et al., 2013).

Taking these important fundamentals into account, it appears to be more reasonable to assess IVI according to a service-oriented approach. The basic formulation adopted in the tests presented in this paper is:

(i) Split the entire system into subsystems with a functional identity (e.g. district metering areas in water distribution systems, drainage sub-catchment basins in wastewater or storm water networks).

(ii) Define / adopt the existing corporate assessment system, with service-oriented objectives, assessment criteria and metrics; select the relevant metrics depending on the infrastructure efficiency and effectiveness.

(iii) Standardise each metric for a 0-3 scale (0 - no service; 1 : limit between unacceptable and acceptable; 2: limit between acceptable and good; 3 - Excellent).

(iv) All metrics should be relevant and balanced between them but, if necessary, give different relative weights to some metrics.

(v) Assess these metrics for each subsystem; standardise results;

(vi) Assess weighted average, i.e., global level of compliance with the objectives for each subsystem; this is taken as the IVI of that area, for the year the data refers to.

(vii) Assess the global IVI using replacement costs of each subsystem as weights.

This approach has the advantage of acknowledging that the value of an infrastructure actually depends on its quality of service (including efficiency and risk considerations). Another advantage is the recognition that useful lives should be an output of service adequacy rather than an input for investment planning. The main disadvantages are: i) it introduces an added level of subjectivity into the process; ii) it does not consider, in the calculation of the IVI at a certain time, the expected evolution of the service; iii) it does not consider the level of investment required to recover the level of service.

\section{ASSET ORIENTED VS SERVICE ORIENTED APPROACH: AN EXAMPLE OF APPLICATION}

\section{Case study description}

The two different approaches to assessing IVI described were tested in three real water distribution systems, with the aim of comparing and discussing the results obtained from each one. A total of 40 District Metering Areas (DMAs) were evaluated. This analysis could also be done at system level. The pipe length of DMAs varies considerably, ranging from 1 to $200 \mathrm{~km}$. It may be considered that these utilities have more accurate data (in quantity and quality terms) than most Portuguese utilities.

The useful lives adopted in asset-oriented calculations were the same for all DMAs and correspond to values defined by utility technicians in iGPI 2015 (as previously presented in Table 1). The definition of replacement costs was based on reference values provided by each utility, as they are considered very well known. Differences between them are not significant.

The assessment system adopted in service-oriented approach, as well as metrics' reference values, are presented in Table 2 . 
Table 2. Assessment system (strategic objectives and metrics) and metrics' reference values.

\begin{tabular}{lll}
\hline Strategic objectives & Metrics & $\begin{array}{l}\text { Reference values } \\
\text { Good; } \text { Fair; } \odot \text { Poor }\end{array}$ \\
\hline $\begin{array}{l}\text { Protection of user } \\
\text { interests }\end{array}$ & $\begin{array}{l}\text { AA03 - Service interruptions } \\
{\left[\mathrm{n}^{\circ} /(\text { connections.year })\right]}\end{array}$ & $[0.0 ; 1.0] \odot] 1.0 ; 2.5[\odot] 2.5 ;+\infty]$ \\
\hline $\begin{array}{l}\text { Operators } \\
\text { sustainability }\end{array}$ & AA08 - Non-revenue water $(\%)$ & $[0 ; 20] \odot] 20 ; 30[\odot] 30 ; 100]$ \\
\cline { 2 - 3 } $\begin{array}{l}\text { Environmental } \\
\text { sustainability }\end{array}$ & AA11- Mains failures $\left[\mathrm{n}^{\circ} /(100 \mathrm{~km} . \mathrm{year})\right]$ & $[0 ; 30] \odot] 30 ; 60[\odot] 60 ;+\infty]$ \\
\hline
\end{tabular}

It should be noted that these four metrics and respective strategic objectives are defined and assessed for regulation purposes. The metrics' reference values were also established in accordance with the National Water and Waste Services Regulation Authority (ERSAR - Entidade Reguladora dos Serviços de Água e Resíduos).

In general, for evaluated DMAs, the metric that presents the best results is service provision, whereas the worse results refer to the non-revenue water indicator.

\section{Results and discussion}

Results obtained from IVI calculations for each DMA are presented in Figure 2. Results presented in each graph only differ in the metrics used to assess service-oriented IVI. In graph (a) the quality of service was only assessed considering the main failures metric, while in graph (b) all mentioned metrics were considered.
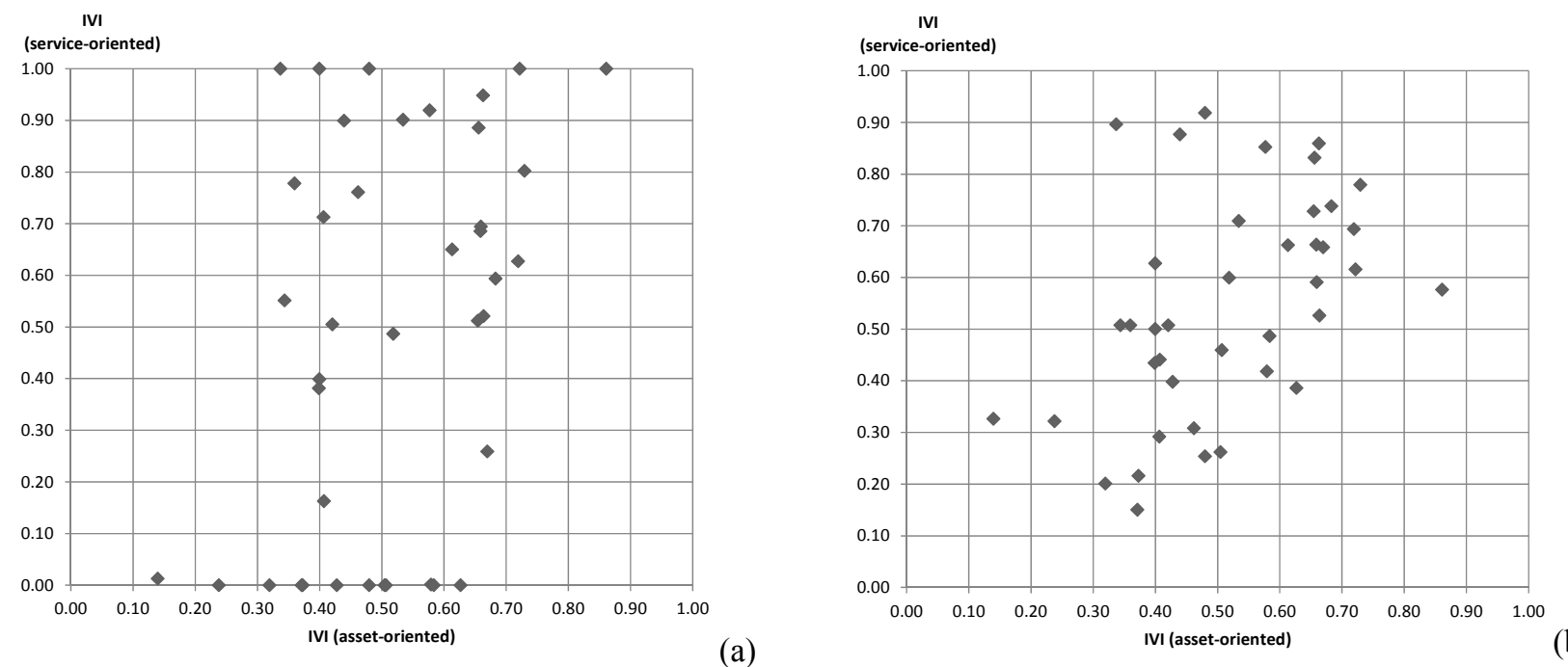

Figure 2. Asset-oriented IVI vs service-oriented IVI (a) calculation only based on AA11 - main failures; b) calculation based on four metrics).

Results obtained through the two assessing approaches shows spread dispersion, particularly when service is measured only considering one metric (as illustrated for main failures). This means that some old functional areas (in average terms) are providing a better quality of service than expected and some more recent areas are providing a worse service than expected. Therefore, it becomes clear that while age of individual assets is an important input, it is not sufficient to infer about the quality of service actually provided by a system or a subsystem. There is no biunivocal relation between these two variables. Among other things, it is important to realize the function of assets in the system. 
Despite dispersion, comparison between results obtained from the two approaches is very useful as it allows the assessing, in general terms, of whether useful lives are well defined for different metrics or groups of metrics. For example if there is a tendency to have higher service-oriented IVI than those obtained through the asset-oriented approach, it can be said that useful lives are underestimated.

When considering a global level of compliance with the objectives based on the four metrics defined in the assessment system, results obtained are less dispersed. As can be seen in Figure 2, results appear to present a more linear trend. This effect probably occurs due to compensation between metrics. A good performance in regards to one metric does not necessarily mean a good performance in another. As an example, Figure 3 illustrates the relation between main failures and real water losses.

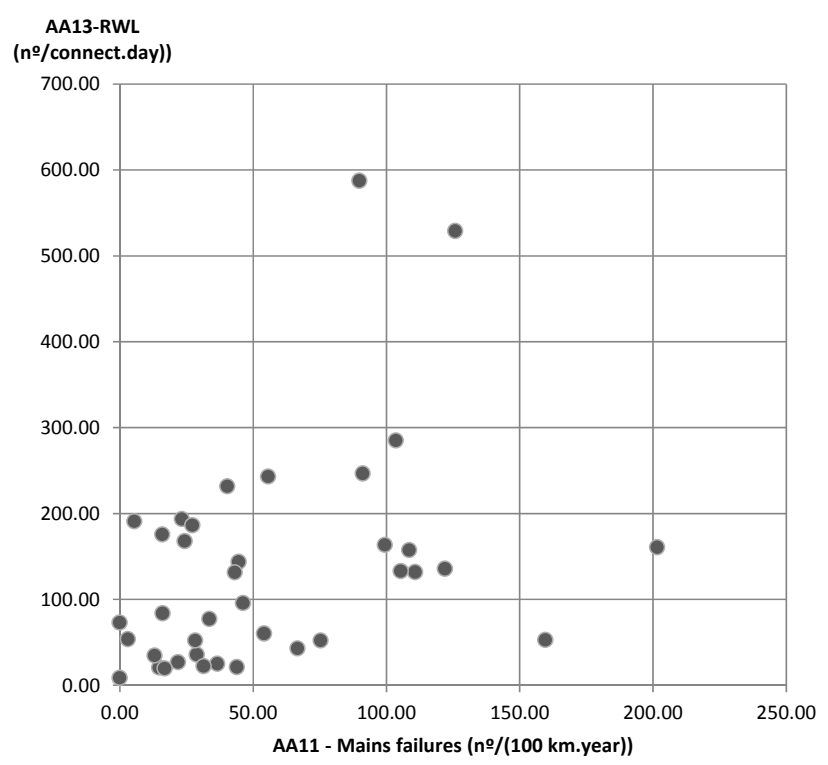

Figure 3. Main failures vs real water losses.

The performed analysis encourages further research work and testing. Following main challenges should be addressed:

- Network vs individual assets - the value of an infrastructure should reflect the quality of service provided by the system, instead of the sum of performance of individual components. However, two systems with the same quality of service, but one with local problems and another with dispersed problems, should present the same value?

- Actual performance vs future performance - the value of an infrastructure for a given time should reflect not only the quality of service actually provided but also its expected evolution.

Applying a service-oriented IVI as a long-term renewal planning tool also requires answer the main following questions:

- How to perform a forecast evolution of IVI over time?

- How to define long term renewal requirements based on the performance of functional areas?

\section{CONCLUSION}

This paper has shown results of on-going research work, which aims to explore a service-oriented approach for assessing the IVI. 
Two different approaches for assessing the IVI were presented and tested in real three water distribution systems, aimed at comparing and discussing the results obtained from each one. The asset-oriented approach has the advantage of being very intuitive and easy to use. In order to apply it, a broad discussion around the concept of 'useful lives' was carried out within the scope of the iGPI Project. Technicians from participating utilities were asked to assign useful lives for different categories of assets, aiming to achieve a global consensus on this issue, at least for a starting point of analysis. Different points of views were discussed, becoming clear the complexity and difficulty associated with this apparently simple concept. The tested service-oriented approach has the advantage of acknowledging that the value of an infrastructure actually depends on its quality of service. Nevertheless, it introduces a level of subjectivity into the process and does not consider the expected evolution of the service and the investment required to recover the level of service. Results obtained from both approaches have shown a spread dispersion, particularly when service is measured only considering one metric. Comparison between results obtained from the two approaches has shown to be very useful as it allows, in general terms, the "calibrating" of useful lives for different metrics or groups of metrics. The tested service-oriented approach represents a mind shift from more traditional approaches that are centered on an asset basis. Despite promising results, there is still a long way to go. Challenges posed by this new way of thinking will be addressed in the scope of a Ph.D.program and as part of the iGPI Project.

\section{Acknowledgements}

The authors would like to thank the Foundation of Science and Technology, Portugal (FCT), which supported this work through a Ph.D. studentship. The authors would also like to thank all participants and sponsors of the projects AWARE-P (www.aware-p.org) and iGPI (www.iniciativagpi.org) and utilities that have provided the data.

\section{References}

Alegre, H. (2008) Water infrastructure asset management. Research Program, LNEC, Lisbon (in Portuguese).

Alegre, H., Vitorino, D. and Coelho, S. (2014) Infrastructure Value Index: a powerful modelling tool for combined long-term planning of linear and vertical assets. In Proc. of the $16^{\text {th }}$ Conf. on Water Distribution System Analysis, Bari, Italy, 14-17 July.

Ambrose, M., Burn, S., DeSilva, D. and Rahilly, M. (2010) Life Cycle Analysis of Water Networks. Retrieved from: https://www.plasticpipe.org/pdf/life-cycle-cost-study.pdf (Accessed on: September, 2015).

AWWA (2012) Buried No Longer: Confronting America's Water Infrastructure Challenge.

Burn, S., Tucker, S., Rahilly, M., Davis, P., Jarrett, R., Po, M. (2003) Asset planning for water reticulation systems - the PARMS model. Water Sci. Technol. Wat. Sci. Tech. Wat. Supply 3(1-2), 55-62.

CSA (2014) Exploring the issues facing New Zealand's water, wastewater and stormwater sector. Castalia Strategic Advisors.

Jones, M., Williams, W. and Stillman, J. (2014) The evolution of asset management in the water industry. Journal AWWA 106(8), 140-148.

Kane, G., Zhang, D., Lynch, D., and Bendeli, M. (2014) Sydney Water's critical water main strategy and implementation - a quantitative, triple-bottom line approach to risk based asset management. Water Asset Management International, 10(1), 19-24.

Kropp, I., Baur, R. (2005) Integrated failure forecasting model for the strategic rehabilitation planning process. Wat. Sci. Tech. Wat. Supply 5(2), 1-8.

MAOTE (2014) PENSAAR 2020. Uma Estratégia ao Serviço da População: Serviços de Qualidade a um Preço Sustentável. Vol. 1, Ministry of Environment Spatial Planning and Energy, Portugal (in Portuguese).

NSW (2014) NSW Reference Rates Manual - Valuation of Water Supply, Sewerage and Stormwater Assets. Department of Primary Industries, a division of NSW Department of Trade and Investment, Regional Infrastructure and Services.

Reksten, H., Ugarelli, R., Fleten, S.-E., and Saegrov, S. (2013). Obstacles to a financially sustainable funding of water supply infrastructure in Norway - Recovering the true full cost. In Proc. of the LESAM 2013. Sydney, Australia.

Renaud, E., Bremond, B. and Le Gat, Y. (2014) Water pipes: why 'lifetime' is not an adequate concept on which to base pipe renewal strategies. Wat. Pract. Tech. 9(3), 307-315.

USEPA (2013) Primer on Condition Curves for Water Mains. Prepared by Thomson, J., Flamberg, S. and Condit, W. WERF (2009) Remaining asset life: a state of the art review. Prepared by Marlow, D., Davis, P., Trans, D., Beale, D., Burn, S. and Urquhat, A., WERF Project SAM1R06d. 